\title{
Creating the Missing Feedback Loop
}

\author{
Alex Jacobs
}

\begin{abstract}
This article describes how agricultural development agencies can implement feedback systems to hear systematically from the intended beneficiaries of their work. Feedback systems relate to debates on reforming accountability, participatory monitoring and evaluation and social accountability. Based on reasoning and the best available evidence, the article argues that in most projects, quantified summaries of smallholder farmers' views can be collected. The data can provide real-time performance indicators which create incentives for staff to focus on the priorities of intended beneficiaries. If acted on, this can improve impact and sustainability. Feedback processes can also be inherently empowering. Leading examples are discussed as are three major challenges: ethical issues, practical issues and management incentives. The article concludes that feedback systems can create an organisational link between participatory processes and management systems. As such, they can make a substantial contribution to improving performance.
\end{abstract}

\section{Introduction \\ Agricultural development agencies appear to have a great deal to gain from setting up feedback systems in their work, so decision- makers can hear directly from farmers and other constituents.}

Feedback systems can significantly boost impact, by creating incentives for staff to focus on beneficiaries' priorities. They can generate powerful measurement data for decision-makers and put the core principle of empowerment into practice. Managers can use the data to monitor how well activities are being implemented and how well they are meeting peoples' actual priorities - allowing them to respond to major risks to impact on development projects.

However, surprisingly, feedback systems are not often implemented in agricultural development agencies. Proven techniques are available and being improved through new technologies. But the established incentives push against using feedback, so the costs currently outweigh the benefits for managers and organisations alike.

This article starts with a short review of the current debate on reforming accountability mechanisms in aid. It introduces the concept of feedback, relating it to 'participatory monitoring and evaluation' (PM\&E) and 'social accountability’. Leading examples are presented of how feedback has been used in development initiatives, along with evidence of its impact. The implications for more general practice are considered. Finally, three key challenges are identified and potential responses discussed. The article ends by suggesting reforms that could strengthen institutional incentives for demandled and people-centred development.

\section{Reforming accountability}

There is an increasingly open and urgent debate about agricultural development agencies' need to reform their accountability mechanisms and, in particular, to be more accountable to poor farmers.

For example, a 2010 global review of agricultural research for development concluded that '.. a change is needed in the incentive structures in the national and international research community to deliver impacts for the poor... [S]ystems need to be more accountable to their beneficiaries' (Lele et al. 2010: 2). A 2008 review made substantial recommendations to reform management and governance across the Consultative Group on International Agricultural Research (CGIAR) System (GGIAR 2008). In 2007, the Farmer First Revisited workshop found that 'farmer first' - or participatory - methods have a crucial role to play but remain the exception rather than the rule in general practice. Ashby noted that bureaucracies 'lacked - and still lack - 
accountability for satisfying demand for innovation from the poor' (Ashby 2009: 39).

These concerns are mirrored in the wider development sector. Barder makes an urgent case to reform bilateral aid, emphasising the need for more appropriate organisational incentives and to fix 'the broken feedback loop connecting the intended beneficiaries and decision-makers' (Barder 2009: 1). Ebrahim describes major shortfalls in the World Bank's accountability mechanisms, noting that while the 'World Bank has ... recognised that empowering the poor to influence the decisions that will affect their lives is a critical dimension of development', its own participatory practice is persistently limited, largely as a result of the incentives that shape staff priorities (Ebrahim 2009: 3). Curiously, as in most agencies, participation is neither monitored nor managed consistently.

The 2008/09 UNIFEM Progress of the World's Women Report argues that the key to ending gender discrimination and achieving the Millennium Development Goals lies in reforming accountability mechanisms, so decision-makers are answerable to women (Goetz 2008).

These arguments draw from a deep literature on development practice. For instance, Ellerman has argued that development interventions are effective when they 'help people help themselves': when they support people's own efforts to improve their lives and respect people's autonomy to make decisions about their own lives. This has the direct implication that external interventions must be sensitively informed by local people's preferences and priorities at every stage of planning, implementation and review, as a cornerstone of success. In other words appropriate 'participation' or accountability to beneficiaries is crucial for impact (Ellerman 2005).

Riddell's vast review of 40 years of efforts to measure 'whether aid works' finds that the studies available 'do not provide a reliable guide on the overall ... contribution of aid to development and poverty reduction. They never will' (Riddell 2007: 254). He argues that the more important question is 'how can aid to poor countries be made effective?'. This strongly suggests that efforts to measure the 'impact' and 'performance' of development agencies could focus on the contribution that agencies make to people and institutions' own efforts, rather than solely on ultimate social changes.

These authors and others argue that development actors face an urgent need to reform how performance is defined and measured and as a result how funds are distributed. Current incentives tend to encourage top-down and technical approaches which have repeatedly proved to have limited impact. The established accountability mechanisms do not encourage development agencies to nurture poor people and farmers' own efforts to tackle poverty and strengthen their self-reliance. There is a wellrecognised conflict between development values of empowerment and participation on the one hand and management and accountability systems on the other.

\section{Feedback systems}

Feedback systems appear to have an important role to play in bridging this gap and reforming incentive systems.

By 'feedback system' we mean a systematic approach to collecting the views of farmers and other key stakeholders about the quality and impact of work undertaken by a development agency, generating quantitative data. The data may describe different dimensions of stakeholders' satisfaction with the work undertaken, in terms that they find meaningful themselves. In other words, the data is based on stakeholders' perceptions and reports of their own experiences. They may be used to inform management decisions about future activities. There are significant ethical considerations in implementing feedback systems in development programmes, discussed below.

Based on reasoning and the best available evidence, our argument is that, in the significant majority of projects, quantified summaries of farmers' views can be collected in a practical and contextually appropriate way. These can represent one important, often excluded, perspective on development agencies' performance. If listened to and acted on, the data will improve impact and sustainability. The process of generating feedback can be inherently empowering, privileging the views of less powerful people and building their confidence to engage with authorities. The data would provide 
powerful performance indicators for donors and senior decision-makers, to inform resource allocation and operational direction. This creates incentives for operational staff and managers to focus their attention on intended beneficiaries and to be responsive to their changing priorities. As a result, feedback systems can create an institutional link between participatory processes and management systems.

To an extent, this argument applies the principles of customer satisfaction from the commercial world to the development context (see Bonbright and Power, this IDS Bulletin).

Feedback systems are a type of PM\&E practice. Estrella and Gaventa trace this approach back to the 1970s. They note that PM\&E is a highly political exercise, involving negotiations about whose views count, and what indicators or social changes are significant, as well as what changes have taken place. As such, it is linked to issues of inclusiveness, power and social transformation. They also note that there is neither a single definition of $\mathrm{PM} \& \mathrm{E}$ nor a single method. $\mathrm{PM} \& \mathrm{E}$ principles have to be adapted to each local context (Estrella and Gaventa 1998). All these issues also apply to feedback systems, as discussed below. Recent innovations in the marriage of quantitative methods and participatory practice have opened up new possibilities, described as a 'quiet revolution' allowing new levels of analysis, aggregation and reporting (Chambers 2007). However, participatory monitoring and evaluation approaches remain more often implemented as one-off pilots than widely applied.

Building on similar principles, interest in social accountability has increased in recent years, linked to the 'good governance' agenda. It suggests that governance can be improved through citizens demanding better representation and service-delivery from service providers. A raft of 'social accountability' initiatives have been trialled over the last two decades including the feedback mechanisms described below. Civil society organisations have vigorously promoted these approaches as mechanisms for making government and private sector actors more accountable to citizens, encouraging powerful actors to listen and respond better to poor people. However, it is striking that these mechanisms have not been widely applied within development agencies. We argue that they could be, for the same reasons. In this way, development agencies could take a major step in reforming their own accountability. They could also strengthen their legitimacy, help citizens develop the confidence to hold power to account and develop new models of good practice.

\subsection{Examples}

The examples below describe feedback systems that have worked and could be applied to agricultural programmes. They illustrate how feedback systems can work in development settings. They are neither comprehensive nor all taken from agricultural interventions. There is limited evidence about the impact of feedback systems and few examples of how these systems have been used to monitor performance within development agencies rather than government programmes.

\subsubsection{Citizen report cards}

Citizen report cards were developed by the Public Affairs Centre, an NGO, in Bangalore in 1993. The method generates satisfaction ratings about public services from a random sample of users, using market research survey techniques. It has been used to provide feedback on government service provision in areas such as health, water and education, as well as agricultural extension services. By 2007, it had been widely disseminated by the World Bank, the UN, civil society and others, and used in at least 16 countries around the world. (ADB 2007: 4)

Citizen report cards have generated quantified data on areas such as the levels of services received, satisfaction with those services and bribes paid. For example, in Ethiopia in 2005 feedback was collected from over 2,300 farmers on agricultural extension services. Ninety-one per cent of farmers reported that an extension agent was available in their locality. Fifty-three per cent reported that the agent visited them once a month or less often, with 22 per cent saying that the agent never visited. Overall satisfaction was low with 22 per cent of farmers saying they were 'completely satisfied' and 47 per cent that they were 'dissatisfied'. Roughly one fifth of farmers had borrowed money for agriculture and related activities, and formal marketing support was largely absent. All findings were broken down by region, allowing 


\section{Box 1 Community scorecard: five steps}

1 Planning and preparation. This includes meeting key stakeholders, training facilitators, identifying service and input entitlements.

2 Community scoring. This starts with a participatory appraisal to identify indicators for assessment. Community groups use the indicators to score service delivery on quantitative scales, disaggregated by wealth and gender.

3 Service provider scoring. Step 2 is repeated with local service provider staff.

4 Interface meeting. Service users and providers discuss results and develop a joint action plan for improvements.

5 Follow up. The action plan is monitored. The process is written up and repeated.

Source CARE Malawi (2007).

for comparison and benchmarking. The results have been used to lobby government agencies for pro-poor improvements in service provision and there are plans to repeat the report card process to monitor progress (Bekele 2006).

Citizen report cards have also been used as one component of the Balanced Scorecard approach, for instance, to monitor health provision in Afghanistan within their Poverty Reduction Strategy Plan. Using a participatory process, stakeholders jointly selected indicators including 'overall patient satisfaction', 'patient perception of quality' and 'health worker satisfaction', alongside more objective measures like drug availability and training provision (Peters et al. 2007).

An independent assessment by the World Bank found that, following report card exercises, many public agencies in Bangalore in India initiated reform measures and that 'Bangalore has witnessed a number of improvements' (Ravindra 2004: ii). The report cards helped to increase public awareness of the quality of services and stimulated citizen groups to demand better services. However, a follow-up report card also found that in some cases, corruption had increased. Results depended on external factors including the use of information by the media and civil society, the responsiveness of agencies and their leaders, the individual context and the resources available. This suggests that report cards can increase the pressure for reform and support the efforts of internal reformers, but are unlikely to force reform on unwilling or constrained public leadership.
Citizens' satisfaction ratings have been found to increase with improvements in the services households receive, but also to be influenced by other factors, such as the services that neighbours receive (Deichmann and Lall 2003). This suggests that satisfaction data should be reviewed with judgement rather than taken as objective.

\subsubsection{Community scorecards}

Community scorecards were developed by CARE in Malawi in 2002, on a project to strengthen healthcare in poor rural communities. They adapted the citizen report card method. The scorecard focuses more on bringing service providers and users together at a local level to strengthen understanding, reinforce shared responsibilities and identify improvements. The five-step process has developed into a methodology applied across many different countries (see Box 1).

This experience identified specific weaknesses in service delivery as perceived by users, such as poor attitudes among health centre staff, limited communication between health service providers and users, and little trust in health service providers. The interface meeting, described as 'the most important stage' in the process, generated a locally owned action plan. When the scorecard was repeated six months later, improvements were recorded in indicators such as staff observing working hours (community rating increased from 40 to 60), how well staff listen to patients (community rating increased from 50 to 85), and some improvements in the 
availability of drugs and equipment.

Comparisons were usefully made between two different clusters of health centres during each of the scorecard processes.

A project report found that the scorecards were 'very useful and important' for planning, monitoring and evaluating the project's performance. It also identified challenges, including sustainability, involving the poorest and most vulnerable people, influencing policy, and extending the model under different conditions (Shah 2003).

A wider review by the World Bank concluded that these approaches 'are powerful and flexible instruments to promote social accountability in the delivery of services to poor communities, and thus to improve the achievement of pro-poor development outcomes' (Thindwa et al. 2005: 15).

In 2005, an evaluation examined the impact of community scorecards ${ }^{1}$ through a randomised field experiment in 50 communities from nine districts in Uganda, focused on primary healthcare. It concluded that:

[T] he community-based monitoring project increased the quality and quantity of primary health care provision. A year after the first round of [community] meetings we find a significant difference in the weight of infants ... and a 33 per cent reduction in under five mortality in the treatment communities. Utilization for general outpatient services was 20 per cent higher $\ldots$ and the overall effect across a set of utilization measures is large and significantly positive' (Björkman and Svensson 2009: 1).

The authors suggest that these impressive results, at both output and outcome levels, are more cost effective than the results achieved by many other health interventions.

CARE Malawi is currently applying the method in a food security project, using scorecards to evaluate itself and village committees. For instance, communities are assessing seed banks against criteria they have identified such as the quality and quantity of seeds, and the training they receive. ACDI/VOCA, another international NGO, is using similar methods to assess its performance providing agricultural extension services to poor communities in the Philippines. ${ }^{2}$ These organisations are trail-blazers in using the methodology to generate management information within their own programmes.

\subsection{Other examples}

A 1995 study in Burkina Faso and Guinea found that farmers' subjective perceptions of new varieties of sorghum and rice significantly affect their adoption decisions (Adesina and BaiduForson 1995). In Senegal, detailed analysis came to the same conclusion that farmers' perceptions were an important factor in adoption rates and also that these perceptions can be quantified in ways that make them accessible to programme teams (Sall et al. 2000). These findings underline instrumental reasons for development agencies to monitor farmers' perceptions.

The World Bank has over 20 years' experience of 'beneficiary assessment', an approach to assessing the value of activities as perceived by their principal users (Salmen 2002). The approach draws on a wide variety of contextspecific methods, generating both qualitative and quantitative data. However, it has remained marginal to the Bank's core operations, arguably for the reasons outlined by Ebrahim (Ebrahim 2009).

The World Food Programme and CARE developed the 'coping strategies index' which uses community perceptions to generate a rapid indicator of household food security, particularly useful for emergency humanitarian responses. It generates structured responses - or feedback by asking people the single question 'What do you do when you don't have enough food, and don't have enough money to buy food?' Studies have shown that this data correlates significantly with other indicators such as food frequency and asset ownership. It cuts across individual dimensions of food security and generates a more comprehensive picture of the issues people face (Maxwell and Caldwell 2008).

Recent innovations in related fields demonstrate similar possibilities. In the microfinance sector, a suite of tools for 'client assessment' has been developed, including client satisfaction, to help report and manage performance (Woller 2005). A Bangladeshi social movement provides a particularly compelling case. They generate quantified data from participatory processes about 


\section{Box 2 ALINe's good practice principles}

Based on an extensive review of current practice and our own experience, ALINe has identified six good practice principles for implementing feedback systems:

1 Adapt systems to the context

2 Develop assessment criteria with respondents

3 Generate quantitative feedback data

4 Report and publish comparative data

5 Discuss findings with respondents and identify actions

6 Repeat the process

These principles summarise practical responses to common difficulties in generating ethical, powerful and actionable feedback data.

Further information: www.alineplanning.org/feedback (accessed 16 August 2010).

people's experiences of social organisation and empowerment, using a framework that was built from the bottom up. The data is used to report performance to donors as well as to monitor individual staff performance, while all the time building the skills and confidence of the people the movement works with (Jupp et al. 2010).

\section{Implications}

The examples show how development organisations can use feedback systems to generate performance data on how satisfied intended beneficiaries are with how activities are implemented and what they are achieving.

A wide range of indicators have been monitored by asking people for their views, rather than measuring around them. Carefully used, these perception-based indicators are empowering and strengthen dialogue between local people and service providers about what works in the local context and why.

They can be used to measure outcomes (like income changes, nutritional intake and empowerment); outputs (like technology adoption, access to services and capacities); and operational effectiveness (like the quantity and quality of services received, and the quality of participation). All data can be disaggregated by gender, to generate powerful management information that describes women's and men's different experiences of development efforts. For instance, imagine the impact on gender mainstreaming if agencies' funding was directly linked to poor women's assessments of their work.

The approach appears to be useful for advocacy and capacity-building interventions as well as direct service delivery, for instance, by collecting systematic feedback on the quality of policy advice or training by those intended to benefit from it. However, as Olken pointed out, the approach may not be appropriate in all cases, for instance for auditing road construction or building a bridge once it has been designed (Olken 2007). His findings also flag up the practical issues discussed below and addressed by ALINe's six feedback principles (see Box 2).

We recognise that the approach may not be appropriate in all cases or for all parts of all projects. For instance, once a bridge has been approved, the technical job of building it may not necessarily be improved by greater participation and feedback.

Feedback data are necessarily subjective. We argue that they are one important source of data for decision-making among others, which has to be interpreted in context. Projects are also likely to have to monitor a number of other indicators such as key milestones in project delivery and the reach and scope of project activities. Evaluations 
can establish impacts. The subjectivity can be an advantage in allowing managers to understand more about which groups are gaining and losing from a project, giving insights into unavoidable local political issues (Roche 1999).

Feedback can bring significant advantages in generating real-time data to demonstrate whether interventions are being well implemented and meeting peoples' priorities, informing management oversight and testing the theory of change. History suggests that these are major risks to most development projects, greater risks than the initial plan being reliable and well executed but still not achieving the expected outcomes. Two acid tests may be: (i) Would you personally expect your views to be considered on any major programme impacting on your life? and (ii) If development agencies work for public benefit, similar to government agencies, then shouldn't the same standards of transparency, consultation and accountability apply?

\section{Challenges}

Feedback systems raise significant ethical issues, mirroring concerns in participatory practice. Agencies may solicit the views of people who do not represent the intended respondents or beneficiaries. Women are particularly likely to be excluded at all stages (developing assessment criteria, giving feedback and discussing findings). The assumption that 'a community' holds a single view may squeeze out marginal groups or reinforce the power of dominant groups. Farmers' time must be respected and their informed consent requested. Badly implemented feedback systems can generate misleading data for decision-makers and deepen powerimbalances to the detriment of the most poor and vulnerable people. Arguably, all feedback systems - and all development projects - should undergo an ethical review before they are implemented. Keystone's ethical framework provides one practical approach (Keystone 2009).

There are practical difficulties in collecting feedback, particularly from the poorest and most marginalised people. These include: survey methods, which can be complicated, requiring skilled design and piloting; data collection exercises may need to be carefully planned and facilitated to create conditions for more open feedback; the most marginalised may speak local languages or dialects, rather than official languages; access may be constrained by practical or cultural issues; there are likely to be competing demands on management and staff time at different stages of the project cycle.

Similar practical issues have been faced and creatively tackled by participatory practice. There are a wide range of previous experiences to draw on such as costs reduction by using modern technology, including mobile phones. However, there are no blueprint approaches that can be taken off the shelf without being adapted to the local context. This is a serious barrier to implementing feedback systems, raising costs. It may be possible to develop more simple and replicable techniques which strike a reasonable compromise between quality, cost and applicability.

The most significant barrier to implementing feedback systems appears to be the incentives that shape management and organisational behaviour. Currently, in institutional terms, the costs consistently outweigh the benefits, particularly when managers are handling many different priorities. Managers and organisations are rewarded more for other behaviours, such as implementing project plans agreed with donors on time and in budget, and raising their public profile. Funding tends to be increasingly short term and restricted to pre-determined activities, limiting opportunities for responding to farmer feedback. Organisations continue to win funds without robust evidence about their performance on the ground. Recent empirical research in Uganda has shown no significant correlation between NGOs' organisational survival and the value that their intended beneficiaries perceive from their work (Burger and Owens forthcoming). This appears to be indicative of incentive systems that shape aid more widely. For example, see discussion of efforts to reform gender in an international NGO (Wallace and Wilson 2005), strengthen participation in the World Bank (Ebrahim 2009), and improve the UN's engagement with small farmer organisations (McKeon 2009). These suggest that a central factor in reforming development bureaucracy is tackling the current reliance on 'supply-led' performance monitoring based on the question 'did the agency carry out the activities agreed in the project plan?' 
Incentives could potentially be reshaped by reforming accountability mechanisms so they encourage and reward demand-led development, for instance by:

- donors and senior managers consistently requiring quantified reports of farmer satisfaction;

- implementing agencies publishing reports of farmer satisfaction, creating a new norm in their practice;

- civil society actors collecting and publishing feedback data independently of donors and implementing agencies;

- demonstrating the value added by feedback and celebrating successes; and

- developing cheaper and simpler feedback tools.

These reforms align with other efforts to improve 'donorship' and implementation, such as involving external actors in planning and reviewing performance (e.g. Outcome Mapping and Participatory Impact Pathway Analysis), strengthening financial transparency (the International Aid Transparency Initiative), creating complaints mechanisms (the

Humanitarian Accountability Partnership), and requiring regular project reviews that involve all stakeholders in the expectation that plans and budgets will be significantly adapted (ActionAid's Accountability Learning and Planning System). Collectively, they require significant change to management structures and practices within implementing agencies and donors, for instance prioritising facilitation and participatory skills, and reinforcing the core value of supporting autonomous self-determination.

\section{Notes}

1 This article uses the terms 'community monitoring' and 'citizen report card' to describe the method laid out as 'community scorecard' in the literature and above.

\section{References}

Adesina, A. and Baidu-Forson, J. (1995) 'Farmers' Perceptions and Adoption of New Agricultural Technology: Evidence from Analysis in Burkina Faso and Guinea, West Africa', Agricultural Economics 13: 1-9

Ashby, J. (2009) 'Fostering Farmer First Methodological Innovation: Organizational Learning and Change in International Agricultural Research' in I. Scoones and J.

\section{Conclusion}

Suggestive evidence and reasoning make a powerful case that feedback systems can unlock the core problems of accountability in agricultural development and significantly increase impact.

The tools and techniques for implementing feedback systems exist. While there are no offthe-shelf solutions, there is a wide range of experience of how good practice principles can be applied in different contexts.

However, agricultural development agencies lack the incentives to use feedback systems. The established systems for assessing performance and allocating funds do not encourage agencies to listen and respond to farmers and other intended beneficiaries.

This article has argued that using feedback to monitor performance could create the incentives for demand-led and people-centred development. This could be a realistic corrective to the approach of measuring performance compared to original plans, which creates incentives for supply-led and agency-centred development.

One powerful reform would be for donors and senior decision-makers to consistently require quantified reports of farmer satisfaction. Progress will rely on leadership and innovation at the most senior level. Alternatively, a groundswell of demand from the bottom up could force change.

2 Both initiatives are described in the ALINe Farmer Voice Awards in 2010, recognising their work to listen and respond to farmers: www.alineplanning.org/awards (accessed 16 August 2010).

Thompson (eds), Farmer First Revisited: Innovation for Agricultural Research and Development, Oxford: ITDG Publishing ADB (2007) Citizen Report Card Learning Toolkit, Manila, Philippines: Asian Development Bank (ADB)

Barder, O. (2009) Beyond Planning: Markets and Networks for Better Aid, Working Paper 185, Washington DC: Centre for Global Development 
Bekele, E. (2006) 'The Case of Gitizen Report Cards in Ethiopia', paper presented at Human Development and Capability Association 2006 annual meeting, 29 August-1 September

Björkman, M. and Svensson, J. (2009) 'Power to the People: Evidence from a Randomized Field Experiment on Community-based Monitoring in Uganda', Quarterly Journal of Economics 124.2: 735-69

Burger, R. and Owens, T. (forthcoming) 'Receive Aid or Perish? Investigating Survival Prospects of African NGOs without Grants', unpublished

CARE Malawi (2007) The Scorecard Toolkit, www.sasanet.org/curriculum_final/downlaods/ SM/Books\%20\&\%20Articles/SM\%20Ar4.pdf (accessed 3 September 2010)

Chambers, Robert (2007) Who Counts? The Quiet Revolution of Participation and Numbers, IDS Working Paper 296, Brighton: IDS

CGIAR (2008) Bringing Together the Best of Science and the Best of Development: Independent Review Panel Synthesis Report, Washington DC: Consultative Group on International Agricultural Research (CGIAR)

Deichmann, U. and Lall, S. (2003) Are you Satisfied? Citizen Feedback and Delivery of Urban Services, Policy Research Working Paper 3070, Washington DC: World Bank

Ebrahim, A. (2009) Testimony of Alnoor Ebrahim, associate professor Harvard University before the Committee on Financial Services, US House of Representatives, 10 September 2009, Washington DC, US House of Representatives

Ellerman, D. (2005) Helping People Help Themselves: From the World Bank to an Alternative Philosophy of Development Assistance (Evolving Values for a Capitalist World), Michigan: University of Michigan Press

Estrella, M. and Gaventa, J. (1998) Who Counts Reality? Participatory Monitoring and Evaluation: A Literature Review, Brighton: IDS

Goetz, A.-M. (2008) Who Answers to Women? Gender and Accountability, New York: United Nations Development Fund for Women (UNIFEM)

Jupp, D.; Ali, S.I. and Barahona, C. (2010) Measuring Empowerment? Ask Them, Stockholm: Swedish International Development Cooperation Agency (Sida)

Keystone (2009) Keystone's Ethical Framework for Constituency Feedback, www.keystoneaccountability.org/sites/default/ files/Keystone\%20ethical\%20framework\%20 Aug09\%20web.pdf (accessed 3 September 2010)
Lele, U.; Pretty, J.; Terry, E. and Trigo, E. (2010) Transforming Agricultural Research for Development: Executive Summary, Rome: Global Conference on Agricultural Research (GCARD)

Maxwell, D. and Caldwell, R. (2008) The Coping Strategies Index: Field Methods Manual, 2nd edn, CARE, http://documents.wfp.org/ stellent/groups/public/documents/manual_ guide_proced/wfp2 11058 .pdf (accessed 3 September 2010)

McKeon, N. (2009) Strengthening Dialogue: UN Experience with Small Farmer Organizations and Indigenous Peoples, New York: UN NonGovernmental Liaison Service (NGLS)

Olken, B. (2007) 'Monitoring Corruption: Evidence from a Field Experiment in Indonesia', Journal of Political Economy 115.21

Peters, D.; Noor, A.; Singh, L.; Kakar, F.; Hansena, P. and Burnhama, G. (2007) 'A Balanced Scorecard for Health Services in Afghanistan', Bulletin of the World Health Organization 85

Ravindra, A. (2004) An Assessment of the Impact of Bangalore Citizen Report Cards on the Performance of Public Agencies, ECD Working Paper 12, Washington DC: World Bank

Riddell, R. (2007) Does Foreign Aid Really Work?, Oxford: Oxford University Press

Roche, C. (1999) Impact Assessment for Development Agencies, Oxford: Oxfam

Sall, S.; Norman, D. and Featherstone, A. (2000) 'Quantitative Assessment of Improved Rice Variety Adoption: The Farmer's Perspectives', Agricultural Systems 66: 129-44

Salmen, L. (2002) Beneficiary Assessment: An Approach Described, Social Development Paper 10, Washington DC: World Bank

Shah, M. (2003) Using Community Scorecards for Improving Transparency and Accountability in the Delivery of Public Health Services: Experience from Local Initiative for Health (LIFH) Project, CARE Malawi, GARE Malawi

Thindwa, J.; Edgerton, J. and Forster, R. (2005) Community Based Performance Monitoring (CBPM): Empowering and Giving Voice to Local Communities, Washington DC: World Bank Social Development Department

Wallace, T. and Wilson, P. (2005) 'The Challenge to International NGOs of Integrating Gender', in A. Coles and T. Wallace (eds), Gender, Water and Development, Oxford: Berg Publishers

Woller, G. (2005) Building Successful Microfinance Institutions by Assessing Clients' Needs, Washington DC: The SEEP Network 